\title{
COUNTERMEASURES TO IMPROVE ROAD ALIGNMENT CONSISTENCY OF UNDIVIDED RURAL ROADS
}

\author{
Francesca Russo $^{1}$, Salvatore Antonio Biancardo ${ }^{2}$ \\ Dept of Civil, Architectural and Environmental Engineering, University of Naples Federico II, \\ Via Claudio, 21, 80125 Naples, Italy, \\ E-mails: ${ }^{1}$ francesca.russo2@unina.it; ${ }^{2}$ salvatoreantonio.biancardo@unina.it
}

\begin{abstract}
The research aims to assess the relationships between the crash rates and road consistency. Design consistency assessment is a tool employed by designers to improve road safety. The case study involved a rural two-lane two-way road in Southern Italy located on a flat terrain without spiral transition curves between tangent segments and circular curves. Road alignment consistency was examined in two steps: by adopting standards in force in Italy based on the design speed profile and by plotting operating speed profile to determine the area bounded by the speed profile and the average weighted speed, and the standard deviation of operating speeds for each geometric segment. Operating speed prediction model, which returns the $85^{\text {th }}$ percentile of the speed distribution of the only cars under free flow conditions, right weather conditions, and lighting was adopted. A negative exponential function was performed to predict the global consistency of a road as a whole. Finally, a model for predicting the crash rate was calibrated, confirming an increase of design consistency when the crash rates decrease significantly. The consistency model represents a useful tool during the geometric design process or the evaluation process for two-lane rural highways.
\end{abstract}

Keywords: alignment consistency, crash rate, undivided rural road.

\section{Introduction}

The case study presented here is a result of a broader research programme under way from several years now (Dell'Acqua et al. 2011a; Dell'Acqua et al. 2011b; Discetti et al. 2011), and it is focused on the application of sequential methodologies to investigate the best geometric configuration of an existing rural road alignment matching at the same time geometric and safety requirements. The research focused on an undivided rural located in the Southern Italy, almost $3 \mathrm{~km}$ long almost, placed on a flat terrain with a vertical grade less than $3 \%$ and under low-volume conditions. The primary objective was to explore an alternative road geometric profile to improve consistency and safety conditions. A model for predicting the crash rate was adopted to assess how the change in road geometric consistency positively effect on the traffic safety. Comparisons between road scenario before and after adjustments were carried out regarding changing configurations and expected crash rate.

According to Highway Safety Manual (HSM 2010) of American Association of State Highway and Transportation Officials, the likelihood of drivers responding to situations and information correctly and quickly increases when the road design corresponds with driver limitations and expectations. One way to accommodate to human information processing limitations is to design roadway environments by driver expectations: the design of a road in according to the standards and, consequently, reflecting the expectations of drivers, creates a proper alignment consistency (HSM 2010).

Castro et al. (2013), Morris and Donnell (2014), Russo et al. $(2015 ; 2016)$ have verified the operating speed as one of the parameters to most influence a safe driving. One of how operating speeds are used in ensuring design consistency is using speed profiles. Speed-profile models are used to detect speed inconsistencies along road alignments. Design inconsistencies are identified on the speed profile when there are significant differentials in operating speeds among successive alignments features by the Speed Prediction for Two-Lane Rural Highways, by the Federal Highway Administration United States, Dept of Transportation of 2000.

Therefore, designing highways to influence driveroperating speed efficiently through environmental feedback is a key research field requiring particular attention (Stamatiadis, Hartman 2011).

According to the aim of the research presented here, roadway design should "look and feel" like the intended purpose of the roadway consistent with driver expectations and commensurate with the function of the road. 
The research was divided into several steps:

1) assessing road geometric inconsistencies according to the Italian road geometric design standard;

2) assessing a local measure of road consistency based on the speed difference among two following geometric elements;

3) assessing a global measure of the alignment consistency by adopting a prediction model based on the sensitivity analysis;

4) evaluating real crash rate associated with the total road length;

5) varying road geometric configuration for increasing the total consistency;

6) comparing the expected crash rate with the first one measure.

The crash rate equals to the number of crashes per year per $\mathrm{km}$ per $10^{8}$ vehicles (crash frequency over traffic exposure) is interpreted as the probability (based on past events) of being involved in a crash per instance of the exposure measure. The results of the research study here presented confirmed with the increasing road geometric design consistency by improving the alignment, expected crash rate decreases.

A design inconsistency in a roadway segment usually results from geometric features vary significantly and therefore cause drivers to make speed errors or unsafe driving manoeuvres leading to higher collision risk (Dell'Acqua et al. 2013; Dell'Acqua 2015; Mattar-Habib et al. 2008).

An essential aspect of improving highway safety lies in designing the geometric features of roadways in response to the characteristics and behaviour of drivers (Hassan et al. 2001).

When the various elements are in juxtaposition, the driver adequately communicate with the highway and recognize its different components accurately, so the composition of the road provides coordination and balance during driving (Leisch 1977).

Polus and Mattar-Habib (2004) and Dell'Acqua et al. (2013) developed a consistency model for two-lane rural highways. The starting point of the analysis was the prediction of operating speeds on circular curves and tangents by applying models available in the literature or calibrated ad hoc for the study roads. Two independent measurements were proposed to evaluate consistency: the relevant area bounded by the speed profile and the average weighted speed lines, with the standard deviation of speeds along a highway segment. Following an extensive sensitivity analysis of these two measures, thresholds quantifying the design quality were suggested. Based on the two independent measures, a consistency model was developed and thresholds for good, acceptable, and poor design consistency of any section were proposed.

Park and Saccomanno (2006) introduced some issues concerned with establishing speed consistency along with a highway. They compared two primary measures:

1) differential speed profiles using $\triangle \mathrm{V} 85$ (difference in the $85^{\text {th }}$ percentile speeds observed among successive elements of the road);
2) 85 maximum speed reduction $\left(85^{\text {th }}\right.$ percentile MSR between two following highway elements as experienced by the same vehicle or driver).

$\mathrm{Wu}$ et al. (2013) analysed the relationships between geometric design consistency and traffic safety on two case-study highways in central Pennsylvania, United States of America (U.S. 322 and PA 350). Design consistency was referred to as the difference between operating speed and design speed. Several count regression model formulations were used to explore the statistical association between design consistency and total crash frequency. A statistically significant positive association between geometric design consistency and safety was found. Design consistency surrounding the study elements was also found to increase the expected crash frequency in the study element.

\section{Data Collection}

A total of almost $3000 \mathrm{~m}$ of the two-lane rural road in Southern Italy characterized by an Annual Average Daily Traffic (AADT, in vehicles per day) less than 1400 vpd was involved in the study presented here located on a flat terrain with a vertical grade less than $3 \%$. A total width value of the travel lanes plus shoulders is equal almost to $10 \mathrm{~m}$.

Based on the total number of crashes observed in last five years (4 total number of crashes with five injuries), $A A D T$, total road length, the crash rate is equal to 1.17 crashes per year per $10^{6}$ vehicles per $\mathrm{km}$. A crash rate is a number of crashes per year per km per 106 vehicles.

Spiral transition curves, tangent-to-curve transition sections, and curve-to-curve transition curves are missing along the whole length of the two-lane rural road, which was built before the Road Design Standard (Ministero delle Infrastrutture e Dei Trasporti, 2001) became law. These rules require the design and introduction of spiral transition curves along the horizontal alignment length because they help to provide a gradual change in the alignment curvature and avoid abrupt speed variations, while negotiating the change of curvature.

The study road horizontal alignment consists of three tangent segments and two circular curves, while three vertical sags and one crest compose the vertical alignment. Figure 1 shows a framework of the study road from the horizontal alignment (pink colour in Fig. 1a), on the one hand, and placement in the local territorial area (shown by the red arrow in Fig. 1b), on the contrary.

As Fig.1b shows, the final intersections in $\mathrm{B}$ and $\mathrm{C}$ positions are rural at-grade two-lane two-way three-leg intersections with stop control on the minor approaches. Intersection B appears an unsafe site as follows:

- the circular curve belonging to the main road $A B$ is located close to the intersectionand is hidden from view of drivers. The intersection is not correctly perceived by drivers creating hazardous scenarios since they came from the main road $A B$ where the operating speed values are higher than those achievable on the study road BC characterized by a lower functional level than the first one (Fig. 2c); 


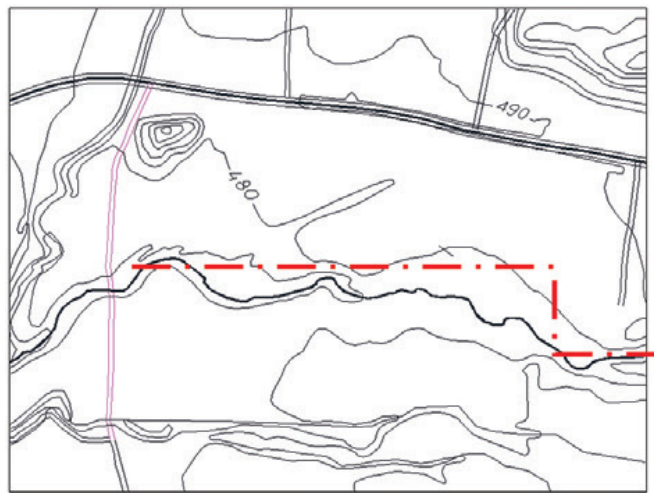

a) horizontal geometric alignment

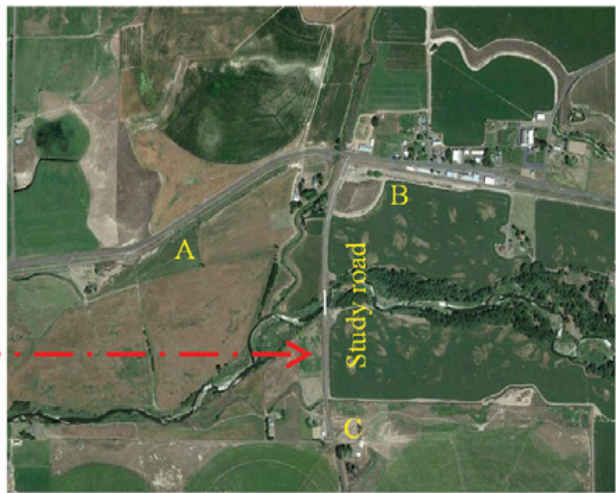

b) surrounding teritorial context

Fig. 1. Study road overview

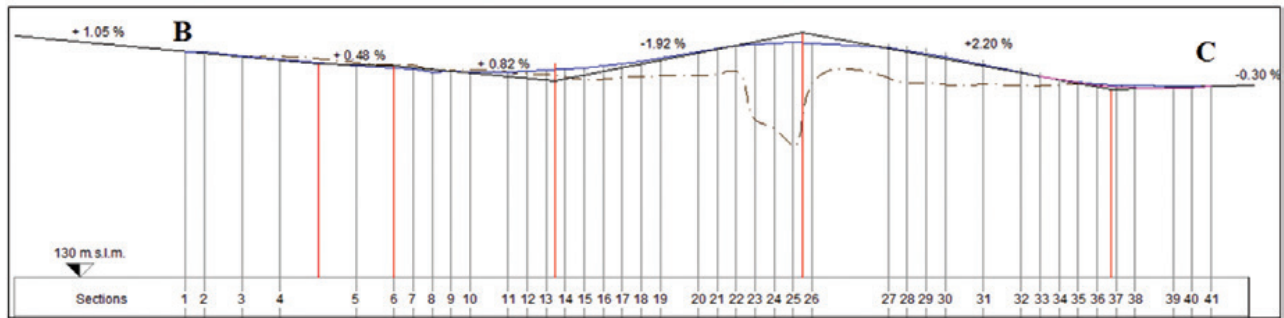

a) excerpt of the vertical alignment of the existing study rural road

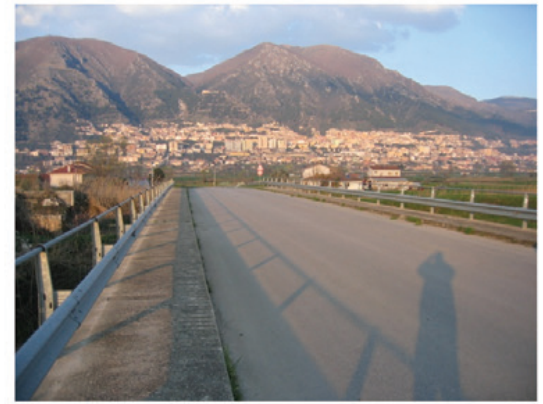

b) crest before sag where unsafe intersection B is placed according to travel direction from $\mathrm{C}$ to $\mathrm{B}$

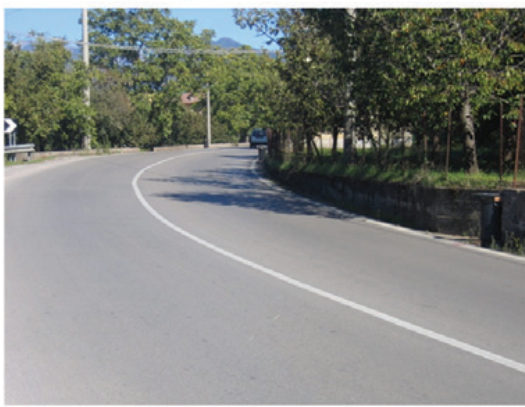

c) circular curve on the major road before intersection B

Fig. 2. Details about alignment of the investigated road

- the intersection B is located in a sag (vertical road alignment in the Fig. 2a) hidden from the view of drivers from $\mathrm{C}$ to $\mathrm{B}$ because of a crest arising near. This hazard scenario causes unacceptable perception of the road alignments and failure in viewing a part of it (Fig. 2b) on the one hand, and on the other hand it further compromises the available sight distance for stopping or slowing down manoeuvres of drivers.

Geometric solutions and position of the current intersection $B$ increase the number of inconsistencies, travelling safety problems and waiting times of vehicles approaching the major road. Several adjustments were carried out as shown below to improve the road geometric consistency and safety conditions.

Table 1 shows a summary of the main geometric features of the geometric road alignment.

The variables in Table 1 are as follows: $L$ is the total element length in meters, $C S$ is the cross-section slope in percentage, $\frac{1}{R}$ is the curvature of the geometric element,
$R$ is the radius of the circular curve, $D S$ is the design speed of the geometric element according to the Italian standard on road geometric design Norme Funzionali e Geometriche per la costruzione il controllo e il collaudo delle strade, D.M. $5 / 11 / 2001, S_{85}$ is the maximum value of the observed operating speed at the middle section of the geometric element in $\mathrm{km} / \mathrm{h}, C C R$ in gon $/ \mathrm{km}$ is the curvature change rate.

Operating speed is the most characteristic parameter of real driving performance, and it is defined as the travel speed of drivers of the only passenger cars on a dry road in free-flow conditions (time headways of $5 \mathrm{~s}$ or more according to the research of Medina and Tarko (2005) during daylight hours. It is calculated by using a specific percentile of speed distribution, typically the $85^{\text {th }}$. Speed data collection was carried out using laser detectors (Fig. 3) in specific environmental and traffic conditions where drivers reach best driving performance (Dell'Acqua 2015): i.e., dry roads, free flow conditions, daylight hours, and right weather conditions. At least 100 observations in free flow conditions at each spot 
were made. Laser detectors were hidden from the view of drivers and placed on a tripod beside the road for two to three hours. Motorcycles and trucks were eliminated from the calculation of the operating speed value at each spot because the primary goal is to check the operating speed values on tangents and circular curves for the highest percentage of the traffic component of the AADT.

The curvature change rate is a variable reflecting the mean tortuosity of the horizontal alignment of a geometric road. Manuscripts are available in the literature where $C C R$ is used to divide the sample into homogeneous segments, investigate the road consistency. To identify homogenous segments, authors referred to indications of the German standard RAS-L - Richtlinien für die Anlage von Strassen, Teil: Linienführung, 1995.

A diagram is plotted: on the $x$-axis, there is the road distance expressed in $\mathrm{km}$, and on the $y$-axis, there is $\mathrm{cu}$ mulative of the absolute value of the angular changes. Only one homogeneous road segment was identified on the investigated rural road with a $C C R$ value of $325.59 \mathrm{gon} / \mathrm{km}$.

By carefully analysing both geometric and vertical alignment of the study road and their juxtaposition, several inconsistencies have been identified according to the
D.M. 5/11/2001, and a proper re-design of the horizontal and vertical alignment was investigated to improve the geometric consistency.

\section{Data Analysis}

Design consistency evaluation is one of the several promising tools to be employed by roadway designers to improve roadway safety performance: design inconsistency in a roadway segment surprise drivers by not meeting their expectations, and increases the chance of delayed response times, speed errors, and unsafe driving manoeuvres leading to higher collision risk. Many researchers have found the speed variable as one of the main parameters influencing safe driving.

A first measure of the road geometric design consistency was obtained by applying Lamm, Choueiri (1987) criteria based on the one hand on the difference between design and operating speed at each geometric element, and on the contrary, on the difference between two operating speed values associated with two consecutive road elements. The consistency is considered good when the difference is less than $10 \mathrm{~km} / \mathrm{h}$, acceptable when the

Table 1. Overview of the main geometric features of the existing study road

\begin{tabular}{|c|c|c|c|c|c|c|}
\hline \multicolumn{7}{|c|}{ Horizontal alignment (Fig. 1) } \\
\hline $\begin{array}{l}\text { Elements } \\
\text { from C to B }\end{array}$ & $\begin{array}{c}C C R \\
\text { gon } / \mathrm{km}\end{array}$ & $\begin{array}{l}L, \\
\mathrm{~m}\end{array}$ & $\begin{array}{c}\text { Cross slope }(C S), \\
\%\end{array}$ & $\begin{array}{l}\frac{1}{R}, \\
\mathrm{~m}^{1}\end{array}$ & $\begin{array}{l}\text { Design speed }(D S) \\
\mathrm{km} / \mathrm{h}\end{array}$ & $\begin{array}{l}\text { Operating speed }\left(S_{85}\right), \\
\mathrm{km} / \mathrm{h}\end{array}$ \\
\hline Tangent 1 & & 216 & 2.00 & 0 & 100 & 84 \\
\hline Circular Curve 1 & & 174 & 4.00 & 0.001 & 97 & 68 \\
\hline Tangent 2 & 325.59 & 1184 & 2.00 & 0 & 100 & 81 \\
\hline Circular Curve 2 & & 48 & 4.00 & 0.001 & 97 & 78 \\
\hline Tangent 3 & & 1375 & 2.00 & 0 & 100 & 63 \\
\hline \multicolumn{7}{|c|}{ Vertical alignment (Fig. 2) } \\
\hline \multicolumn{2}{|c|}{ Elements from $\mathrm{C}$ to $\mathrm{B}$} & $\begin{array}{l}L, \\
\mathrm{~m}\end{array}$ & \multicolumn{2}{|c|}{$\begin{array}{l}\text { First vertical grade, } \\
\%\end{array}$} & $\begin{array}{c}\text { Second vertical grade, } \\
\%\end{array}$ & $\begin{array}{l}\text { Vertical radius, } \\
\mathrm{m}\end{array}$ \\
\hline \multicolumn{2}{|c|}{ sag 1} & 232 & \multicolumn{2}{|c|}{-0.30} & +2.20 & 3000 \\
\hline \multicolumn{2}{|c|}{ crest } & 782 & \multicolumn{2}{|c|}{+0.48} & -1.05 & 8000 \\
\hline \multicolumn{2}{|c|}{ sag 2} & 623 & \multicolumn{2}{|c|}{+2.20} & -1.92 & 3000 \\
\hline \multicolumn{2}{|c|}{ sag 3} & 363 & \multicolumn{2}{|c|}{-1.92} & +0.82 & 3000 \\
\hline
\end{tabular}

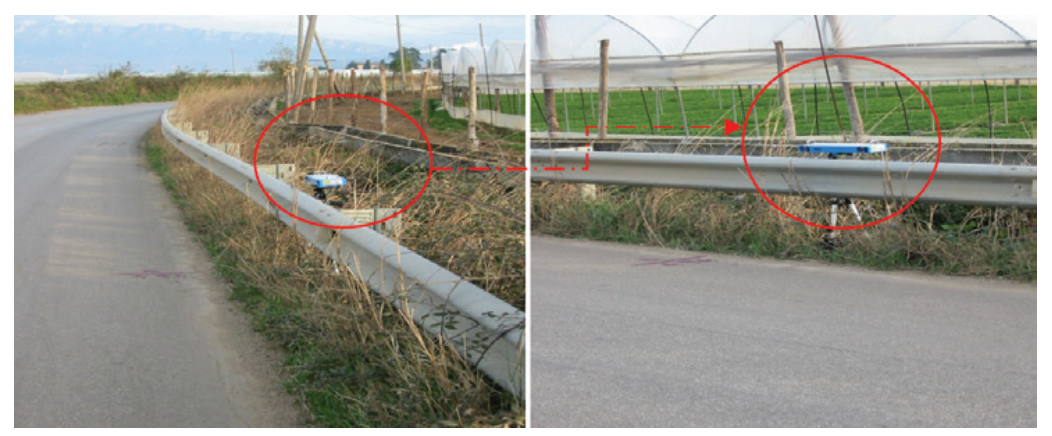

Fig. 3. Detection device for collection speed 
Table 2. Outcomes of the application of Lamm and Choueiri (1987) criteria for assessing the road consistency

\begin{tabular}{|c|c|c|c|c|c|}
\hline \multirow[b]{2}{*}{ ID } & \multirow[b]{2}{*}{$\begin{array}{l}\text { Road elements } \\
\quad \text { (Table 1) }\end{array}$} & \multirow[b]{2}{*}{$\begin{array}{c}D S, \\
\mathrm{~km} / \mathrm{h}\end{array}$} & \multirow{2}{*}{$\begin{array}{c}\text { Maximum value } \\
\text { of } S_{85}, \\
\mathrm{~km} / \mathrm{h}\end{array}$} & \multicolumn{2}{|c|}{ Road consistency according to Lamm-Choueiri criteria } \\
\hline & & & & $\begin{array}{c}\left|D S-S_{85}\right|, \\
\mathrm{km} / \mathrm{h}\end{array}$ & $\begin{array}{c}\left|S_{85 \_i}-S_{85 \_i-1}\right| \\
\mathrm{km} / \mathrm{h}\end{array}$ \\
\hline 1 & Tangent No. 1 & 100 & 84 & 16 & \\
\hline 2 & Circular curve No. 2 & 97 & 68 & 29 & 16 \\
\hline 3 & Tangent No. 2 & 100 & 81 & 19 & 13 \\
\hline 4 & Circular curve No. 2 & 97 & 63 & 34 & 18 \\
\hline 5 & Tangent No. 3 & 100 & 82 & 18 & 19 \\
\hline
\end{tabular}

difference is between $10 \mathrm{~km} / \mathrm{h}$ and $20 \mathrm{~km} / \mathrm{h}$, and poor when the difference is more than $20 \mathrm{~km} / \mathrm{h}$.

The operating speed $S_{85}$ was predicted along the $i^{\text {th }}$ geometric element according to the Eq (1) developed by Russo et al. (2016).

$$
S_{85}=104.59+3.99 \log (L) \cdot 0.07 C C R \cdot 1670\left(\frac{1}{R}\right) .
$$

Equation (1) predicts operating speeds at the same time on tangents and circular curves alike.

Table 2 presents the consistency measures for the analysed road by the Lamm, Choueiri (1987) criteria.

Since one of the primary goals is to associate a unique global measure of congruence with the road as a whole, a mean value of the speed differences was considered and the first hypothesis of the global consistency measure is inadequate.

According to the alternative procedure promoted by Dell'Acqua et al. (2013) and Mattar-Habib et al. (2008), an indicator of overall road geometric consistency, indicated as $C$, was determined by calculating two measures based on operating speed profile. The first measure is the normalized relative area $R_{a}$ per unit length $(\mathrm{Eq}(2))$, restricted between the operating speed profile and the average speed line. The operating speed profile was traced by using the S85 prediction models (Eq (1)), while the average speed line was computed as the average weighted speed, by length, along the entire segment (Fig. 4).

$$
R_{a}=\frac{\sum\left|a_{i}\right|}{L}
$$

where $R_{a}$ is the measure of consistency, in $\mathrm{m} / \mathrm{s} ; a_{i}$ is the areas bounded by the design speed profile and the average speed line (Fig. 4), in $\mathrm{m}^{2} / \mathrm{s} ; L$ is the entire length of each portion of the road, in $\mathrm{m}$.

The second step of consistency is the standard deviation of speeds along the total length (Eq (3)).

$$
\sigma=\sqrt{\frac{\sum_{i=1}^{n}\left(S_{i}-S_{85 \_a v e r a g e}\right)^{2}}{n}},
$$

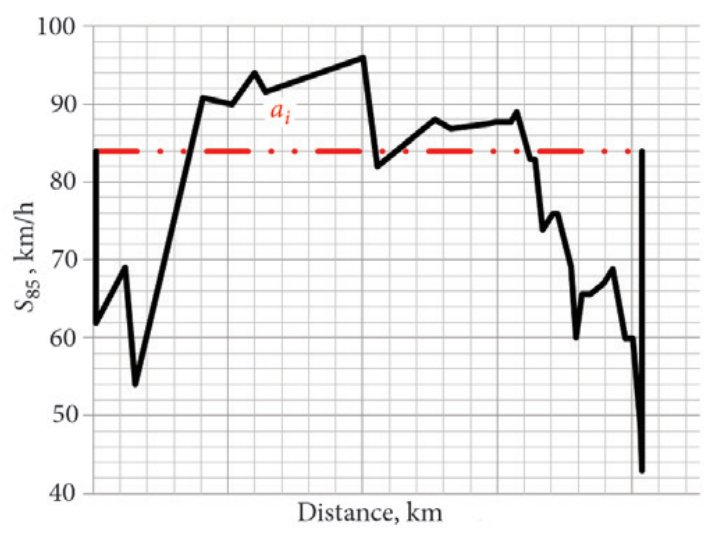

Fig. 4. Example of operating speed profile type and assessing a measure of the consistency

Table 3. Geometric consistency measures

\begin{tabular}{ccc}
\hline \multicolumn{3}{c}{ Thresholds of road consistency } \\
\hline Good & Acceptable & Poor \\
\hline$R_{a}<1$ & $1<R_{a}<2$ & $R_{a}>2$ \\
\hline$\sigma<5$ & $5<\sigma<10$ & $\sigma>10$ \\
\hline Observed values & $R_{a}=2.48$ \\
& $\sigma=8.33$ & POOR \\
\hline \multicolumn{3}{c}{ Design consistency thresholds } \\
\hline Good & Acceptable & Poor \\
\hline$C>2$ & $1<C<2$ & $C<1$ \\
\hline Observed values & $C=0.30$ & POOR
\end{tabular}

where $\sigma$ is the standard deviation of the predicted operating speeds, in $\mathrm{km} / \mathrm{h} ; S_{i}$ is the operating speed value along the $i^{\text {th }}$ geometric element, in $\mathrm{km} / \mathrm{h} ; S_{85 \text { average }}$ is the average weighted (by length) predicted operating speed along a road, in $\mathrm{km} / \mathrm{h}$; $n$ is the number of geometric elements belonging to the road length.

The values of $R_{a}$ and $\sigma$ are shown in Table 3. According to the consistency prediction model $C$ calibrated by Dell'Acqua et al. (2013) and shown in the Eq (4) where previous two measures were adequately combined, the global measure of the overall consistency of the road alignment investigated was calculated. 


$$
C=3 e^{-0.4\left[R_{a}\left(\frac{\sigma}{3.6}\right)\right]} .
$$

Thresholds of the $R_{a}$ and $\sigma$ were defined in the previous research work to set the goodness of the consistency measure. Based on the design consistency thresholds defined in Dell'Acqua et al. (2013) and shown in Table 3, the global consistency of the road alignment is poor reflecting the results achieved by adopting the worst speed difference according to Lamm, Choueiri (1987) criteria.

\section{Results}

The suggested geometric configuration has been hypothesized of the road alignment investigated by adopting geometric design standard in force for improving the global consistency and reducing the crash rate (Fig. 5a).

The expected global consistency measure of the suggested geometric solution was calculated by adopting the Eq (4). The overall consistency increased from 0.30 (existing road path) to 2.22 (suggested solution) as shown in Fig. 5b.

At the same time, the expected crash rate ECR was calculated by adopting the prediction model made available in Polus and Mattar-Habib (2004) and shown in the Eq (5).

$$
E C R=1.051 e^{-0.377 C}
$$

where $e$ is the number of Euler.

The results confirmed a safer road alignment. The predicted crash rate on the re-designed alignment decreased from 1.17 to 0.46 (Fig. 5b).

\section{Conclusions}

The research work is focused on the application of sequential methodologies to investigate the best geometric

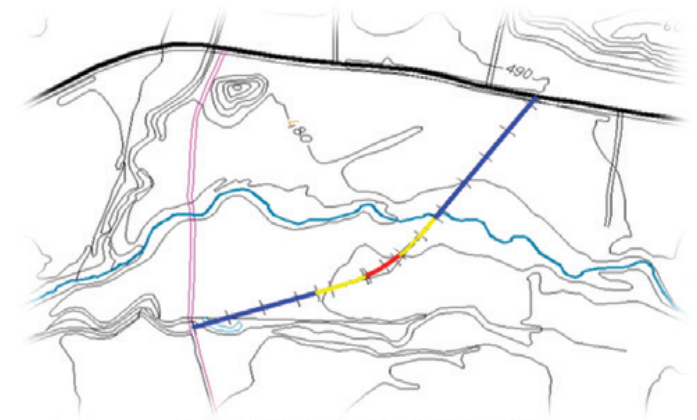

a) suggested geometric alignment

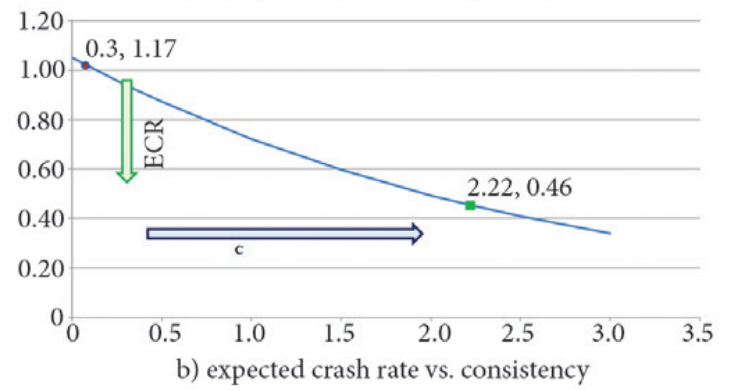

Fig. 5. Redesigning road profile configuration of an existing rural road alignment matching at the same time geometric and safety requirements. A total of almost $3000 \mathrm{~m}$ of the two-lane rural road in Southern Italy was involved in the study. Speed data collection was carried out using laser detectors. An alternative geometric configuration has been hypothesized of the road alignment investigated by adopting geometric design standard in force for improving the global consistency and reducing the crash rate. The results confirmed crash rates are significantly related to consistency and inversely proportional to it: this finding itself justifies, according to the authors, the use of a consistency model both during the geometric design process and during the evaluation process for two-lane rural highways. The predicted crash rate on the re-designed alignment decreased from 1.17 to 0.46 .

\section{References}

Castro, M.; Pardillo-Mayora, J. M.; Jurado, R. 2013. Development of a Local Operating Speed Model for Consistency Analysis Integrating Laser, GPS and GIS for Measuring Vehicles Speed, The Baltic Journal of Road and Bridge Engineering 8(4): 281-288. https://doi.org/10.3846/bjrbe.2013.36

Dell'Acqua, G. 2015. Modeling Driver Behavior by Using the Speed Environment for Two-Lane Rural Roads, Transportation Research Record 2472: 83-90. https://doi.org/10.3141/2472-10

Dell'Acqua, G.; Busiello, M.; Russo, F. 2013. Safety Data Analysis to Evaluate Highway Alignment Consistency, Transportation Research Record 2349: 121-128. https://doi.org/10.3141/2349-14

Dell'Acqua, G.; De Luca, M.; Mauro, R. 2011a. Road Safety Knowledge-Based Decision Support System, Procedia Social and Behavioral Sciences 20: 973-983. https://doi.org/10.1016/j.sbspro.2011.08.106

Dell’Acqua, G.; De Luca, M.; Mauro, R.; Lamberti, R. 2011b. Motorway Speed Management in Southern Italy, Procedia Social and Behavioral Sciences 20: 49-58.

https://doi.org/10.1016/j.sbspro.2011.08.010

Discetti, P.; Dell'Acqua, G.; Lamberti, R. 2011. Models of Operating Speeds for Low-Volume Roads, Transportation Research Record 2203: 219-225. https://doi.org/10.3141/2203-27

Hassan, Y.; Sayed, T.; Tabernero, V. 2001. Establishing Practical Approach for Design Consistency Evaluation, Journal of Transportation Engineering 127(4): 295-302. https://doi.org/10.1061/(ASCE)0733-947X(2001)127:4(295)

Lamm, R.; Choueiri, E. M. 1987. Recommendations for Evaluating Horizontal Design Consistency Based on Investigations in the State of New York, Transportation Research Record 1122: 68-78.

Leisch, J. E. 1977. Dynamics of Highway Design for Safety, Transportation 6(1977): 71-83. https://doi.org/10.1007/BF00165367

Mattar-Habib, C.; Polus, A.; Farah, H. 2008. Further Evaluation of the Relationship between Enhanced Consistency Model and Safety of Two-Lane Rural Roads in Israel and Germany, European Journal of Transport and Infrastructure Research 8(4): 320-332.

Medina, A. F.; Tarko, A. 2005. Speed Factors on Two-Lane Rural Highways in Free-Flow Conditions, Transportation Research Record 1912: 39-46. https://doi.org/10.3141/1912-05

Morris, C.; Donnell, E. T. 2014. Passenger Car and Truck Operating Speed Models on Multilane Highways with Combinations of 
Horizontal Curves and Steep Grades, Journal of Transportation Engineering 140(11).

https://doi.org/10.1061/(ASCE)TE.1943-5436.0000715

Park, Y. J.; Saccomanno, F. F. 2006. Evaluating Speed Consistency Between Successive Elements of a Two-Lane Rural Highway, Transportation Research Part A: Policy and Practice 40(5): 375-385. https://doi.org/10.1016/j.tra.2005.08.003

Polus, A.; Mattar-Habib, C. 2004. New Consistency Model for Rural Highways and Its Relationship to Safety, Journal of Transportation Engineering 130(3): 286-293.

https://doi.org/10.1061/(ASCE)0733-947X(2004)130:3(286)

Russo, F.; Biancardo, S. A.; Busiello, M. 2016. Operating Speed as a Key Factor in Studying the Driver Behavior in a Rural Context, Transport 31(2): 260-270.

https://doi.org/10.3846/16484142.2016.1193054
Russo, F.; Fric, S.; Biancardo, S. A.; Gavran, D. 2015. Driver Speed Behavior on Circular Curves of Undivided Two-Lane Rural Roads. Serbian and Italian Case Studies, Transportation Research Record 2472: 117-128. https://doi.org/10.3141/2472-14

Stamatiadis, N.; Hartman, D. 2011. Context-Sensitive Solutions Versus Practical Solutions: What Are the Differences? Transportation Research Record 2262: 173-180.

https://doi.org/10.3141/2262-17

Wu, K. F.; Donnell, E. T.; Himes, S. C.; Sasidharan, L. 2013. Exploring the Association between Traffic Safety and Geometric Design Consistency Based on Vehicle Speed Metrics, Journal of Transportation Engineering 139(7): 738-748. https://doi.org/10.1061/(ASCE)TE.1943-5436.0000553

Received 15 February 2017; accepted 11 September 2017 